\title{
Resiliência Familiar: o olhar de professores sobre famílias pobres
}

\author{
Larissa Araújo Matos ${ }^{1}$; https://orcid.org/0000-0001-5756-2950 \\ Edson Júnior Silva da Cruz'; https://orcid.org/0000-0003-1884-3172 \\ Thamyris Maués dos Santos'; https://orcid.org/0000-0002-7053-5057 \\ Simone Souza Costa Silva1; https://orcid.org/0000-0003-0795-2998
}

\begin{abstract}
Resumo
O objetivo da presente pesquisa foi descrever a resiliência familiar, do ponto de vista de professores, sobre as famílias de seus alunos. A coleta dos dados foi realizada em uma escola pública, localizada na periferia da cidade de Belém-Pará. Participaram deste estudo onze professores de $1^{\circ}$ ao $5^{\circ}$ ano que responderam a uma entrevista semiestruturada e participaram de uma entrevista coletiva que teve por objetivo obter informações sobre a percepção dos profissionais acerca da resiliência nas famílias dos alunos. Os dados foram coletados e categorizados com base na Análise de conteúdo de Bardin [Análise de conteúdo (2011)] e com o auxílio do software Nvivo versão 10. Os resultados mostraram que os professores compreendemos elementos da resiliência familiar, entretanto, desconsideram tais elementos nas famílias da escola, tendem a ter uma percepção negativa e pessimista sobre as possibilidades de sucesso e resiliência nestes grupos, possuem uma visão estereotipada de família, uma perspectiva estigmatizada sobre pobreza e dos benefícios sociais que estas famílias têm acesso.
\end{abstract}

Palavras-chave: Percepção de professores; resiliência; pobreza.

\section{Family resilience: The look of teachers towards poor families}

\begin{abstract}
This research aims to describe the professor's perspective about family resilience of their student's family. The data collect phase took place in a public school, located in the outskirts of Belém-Pará city. Eleven professors who teaches from the first to the fifth year participated answering a semi-structured interview and speaking their opinions in a group interview dynamic. The data categorization was made accordingly to Bardin [Análise de conteúdo (2011)] and through the software Nvivo 10 version. The results showed that teachers understand the familiar resilience elements but they underestimate those elements in the school's family; tend to have a negative and pessimist perception about the success possibilities and resilience in those groups; have a stereotyped vision of family; a stigmatized perspective about poverty and about the social benefits those family have access.
\end{abstract}

Keywords: Professor's perception; resilience; poverty.

\section{Resiliencia Familiar: la mirada de profesores sobre familias pobres}

\section{Resumen}

El objetivo de la presente investigación fue describir la resiliencia familiar, bajo la mirada de profesores, sobre las familias de sus alumnos. Larecolecta de los datos fue realizada enuna escuela pública, ubicada en los alrededores de la ciudad de Belém-Pará.Participaron de este estudio once profesores de $1^{\mathrm{er}}$ al $5^{\circ}$ curso que respondieron una entrevista semiestructurada y participaron de una entrevista colectiva que tuvo por objetivo obtener informaciones sobre la percepción de los profesionales acerca de la resiliencia en las familias de los alumnos. Se recolectaron los datos y categorizados con base en el Análisis de contenido de Bardin (2011) y con la ayuda del software Nvivo versión 10. Los resultados enseñaron que los profesores comprendemos elementos de la resiliencia familiar, sin embargo, desconsideran tales elementos en las familias de la escuela, tienden a tener una percepciónnegativa y pesimista sobre las posibilidades de éxito y resiliencia en estos grupos, poseen una visión estereotipada de familia, una perspectiva estigmatizada sobre pobreza y de los beneficios sociales que estas familias tienen acceso.

Palabras clave: Percepción de profesores; resiliencia; pobreza.

1 Universidade Federal do Pará - Belém - PA-Brasil; larissa-mattos@hotmail.com; edsoncruzufpa@gmail.com; thamypsi@gmail.com; symon. ufpa@gmail.com 


\section{Introdução}

Resiliência aplicada ao contexto familiar envolve uma visão sistêmica da família em que a cooperação entre seus membros na busca de soluções para problemas compartiIhados pelos sujeitos que compõem esse sistema constitui uma vantagem diferente da resiliência individual que tende a considerar aspectos pessoais dos sujeitos para identificar este fenômeno. Walsh (2005) propõe um modelo para que sejam estudados processos-chave da resiliência em famílias.

A autora especializou-se nesta área e considera três aspectos que precisam ser considerados pelas pesquisas que investigam a resiliência familiar, que são: sistema de crenças da família, padrões de organização e processos de comunicação. O sistema de crenças corresponde à maneira como as famílias encaram seus problemas, de modo que suas escolhas podem fazer a diferença entre o enfrentamento e o domínio da situação ou a disfunção e o desespero diante da dificuldade (Walsh, 2005). Algumas subcategorias do sistema de crenças são: visão otimista, confiança nas adversidades e espiritualidade.

Os padrões organizacionais são considerados por Walsh (2005) como "amortecedores dos choques familiares". Estes padrões dizem respeito ao modo como as famílias se reorganizam diante das adversidades, ou seja, quais recursos sociais e econômicos ela mobiliza para enfrentar os problemas. A autora identifica alguns elementos organizacionais fundamentais para o funcionamento familiar eficiente:colaboração e compromisso, estabilidade e rotina e segurança financeira.

Os processos de comunicação são definidos por Walsh (2005) como troca de informações, e resolução de problemas socioemocionais. Para a autora, a boa comunicação facilita todo o funcionamento familiar, pois fortalece a resiliência familiar, aumenta a competência das famílias em se expressar e reagir às necessidades de mudança em conjunto. Alguns aspectos importantes da comunicação e promotores da resiliência familiar são: resolver conflitos, compartilhar decisões e clareza nas mensagens.

Outros pesquisadoresreforçam a necessidade de entender resiliência como associada à "capacidade do indivíduo em navegar seu caminho em direção a recursos de bem-estar assim como a capacidade de suas comunidades oferecerem esses recursos de formas culturalmente significativas". Portanto, resiliência é vista como resultante daquilo que as comunidades definem como funcionamento saudável e socialmente aceito para suas crianças e adolescentes, bem como a capacidade de suas comunidades em prover recursos significativos (Chequini 2014, Rodovalho Garcia \& Boruchovitch, 2014; Rooke \& Pereira-Silva, 2012; Libório \& Ungar, 2010).

Diante disso, Bronfenbrenner (2011) pressupõe que toda experiência individual se dá em ambientes "concebidos como uma série de estruturas encaixadas, uma dentro da outra, como um conjunto de bonecas russas". Além disso, o autor aponta que "os aspectos do meio ambiente mais importantes no curso do crescimento psicológico são, de for- ma esmagadora, aqueles que têm significado para a pessoa numa dada situação» (p. 51). Portanto, diferentes contextos como família, instituição e escola podem ter influências diversas no desenvolvimento.

Nesse sentido, para definir resiliência familiar é preciso compreender a interação das famílias com o seu ambiente, o que significa entender a dinâmica entre os fatores de risco e de proteção que compõe o contexto no qual o sistema está inserido. A literatura sobre resiliência aponta que estudar este fenômeno é necessariamente investigar fatores de risco, dentre eles, destaca-se a pobreza, que pode ameaçar significativamente o desenvolvimento humano uma vez que esta condição expõe as pessoas a desvantagens sociais e emocionais severas e também pode gerar diversas formas de conflitos nas relações familiares (Angst, 2017; Miranda, 2015; García, Gómez, Gómez, Marín, \& Rodas, 2016).

A despeito das ameaças colocadas pela pobreza ao desenvolvimento, algumas famílias em situação de risco mostram-se muitas vezes hábeis na tomada de decisões e na superação de adversidades, o que evidencia uma unidade familiar e um sistema fortalecido diante das circunstâncias desfavoráveis que enfrentam, pois apresenta fatores de proteção que as auxiliam a construir estratégias diante das dificuldades, como, rede de apoio social em outros contextos, crenças religiosas, espiritualidade, experiências positivas na escola, apoio e afeto positivo entre os membros da família, entre outros. (Yunes, Mendes, \& Albuquerque, 2005; Silva \& cols., 2010; Germano \& Colaço, 2012; García \& cols., 2016). Por isso, Yunes (2003) aponta a importância de se estudar os processos e a dinâmica de funcionamento de famílias pobres, visto que pouco se sabe sobre eles.

Nesse sentido, a interação da família com outros contextos como a escola é relevante para a compreensão dos fatores que auxiliam as famílias diante das dificuldades. A escola é um contexto fundamental de desenvolvimento humano, pois reflete tanto as mudanças na sociedade, ao mesmo tempo em que precisa se adequar a essas transformações. Porém, uma das dificuldades enfrentadas nas escolas é fazer com que professores, alunos e suas famílias estejam aptos a viverem e superarem as adversidades decorrentes de uma sociedade que está em constante mudança, permeada de conflitos interpessoais, sociais e econômicos que influenciam de maneira significativa a relação escola-família (Dessen \& Polônia, 2007; Picanço, 2012).

Nesse contexto, todos os profissionais que atuam, direta ou indiretamente, exercem influência no desenvolvimento de crianças, jovens e adultos. Todavia, os professores parecem ter um contato maior com as famílias, quando comparados aos demais profissionais. Deste modo, os docentes têm papel fundamental em estimular o potencial do aluno, considerar as diferenças socioculturais em que este vive e propor a aquisição de conhecimento através de atividades sistemáticas (Yunes \& Szymanski, 2016; Dessen \& Polônia, 2007). Além disso, segundo Kagan, Henry, Richardson, Trinkle e LaFrenier (2014), o vínculo entre professor e alunos pode ser considerado um fator de proteção para desenvolver características de resiliência para os últimos. 
$\mathrm{Na}$ literatura especializada (Mazzotti, 2006; Zhang, 2012) no que se refere às funções do professor, também é consenso que o exercício destas funções é mediado por suas percepções acerca dos seus alunos. Esta percepção pode fazer com que o professor dê um tratamento peculiar nas interações com os estudantes o que repercutirá no aprendizado direta e indiretamente. Segundo Zhang (2012), o modo como o professor percebe os alunos é revelado nas interações estabelecidas com estes, nas quais são expressadas suas crenças em torno da capacidade de aprender dos estudantes que por sua vez internalizam tais mensagens.

Em um estudo realizado com professores de escolas públicas no Rio de Janeiro, mostrou que os professores têm visões negativas em torno dos alunos e de suas famílias. $\mathrm{Na}$ visão dos professores, as famílias não têm interesse em acompanhar os filhos na escola, não oferecem uma base de conhecimento e são pobres financeiramente e de carinho (Mazzotti, 2006). Esta visão pessimista das famílias repercute na expectativa dos docentes que pouco esperam o sucesso acadêmico dos estudantes, o que implica em uma menor oferta de oportunidades de aprendizagem e consequentemente em baixos níveis de aproveitamento e no rebaixamento da autoestima dos alunos e de suas famílias.

Em outra pesquisa foi apontado que para os professores de uma escola infantil em São Carlos a maioria das famílias atendidas pela escola tem características de "família desestruturada", ou seja, eram compostas por casais separados; o nível socioeconômico baixo, desempregados; os filhos vivenciam muitos problemas, entre os quais se destacam a agressividade, a violência, a droga, o álcool e a prisão (Tancredi \& Reali, 2001). Uma parcela pequena dos alunos é vista como pertencente a famílias tradicionais, do tipo nuclear e com pais atenciosos, isto é, responsivos às solicitações da escola. Nesse estudo é possível perceber que os professores ainda trabalham com uma visão de família ideal e uma única configuração familiar considerada favorável ao desenvolvimento de seus membros, especialmente as gerações mais jovens, entretanto, é importante os professores e a escola estarem conscientes de que existem diversas configurações familiares e que tal conhecimento é necessário para que as relações interpessoais entre os alunos e o contexto escolar ocorra de maneira positiva.

Estudo realizado por Yunes (2001) objetivou conhecer as percepções e crenças de trabalhadores sociais (médico, assistente social, diretores de escola, agente comunitário de saúde) sobre a resiliência em famílias monoparentais pobres. Dentre outros resultados, a pesquisa mostrou que embora esses profissionais compreendam as dificuldades que as famílias de baixa renda enfrentam, prevalece a visão determinista e negativa de que a carência e a acomodação à pobreza são transmitidas de geração para geração. Os profissionais não reconhecem a exploração a que as pessoas de baixa renda estão expostas advindas da maneira como a sociedade capitalista se organiza. Segundo Yunes (2003) é essencial ao profissional reconhecer as reais dificuldades vivenciadas historicamente por essas famílias e, diante disso, estabelecer, no mínimo, uma relação empática e estimuladora capaz de influenciar as famílias a favor da consciência de transformação nesses sujeitos.

Em um estudoque objetivou investigar como as expectativas educacionais de professores no norte rural da China influenciavam nas realizações acadêmicas dos alunos, Tancredi e Reali (2001) verificaram que seus dados observaram que a percepção do professor sobre o estudante, negativa ou positiva, influencia no seu aproveitamento acadêmico e se relaciona com as taxas de abandono escolar. $\mathrm{O}$ estudo mostrou que as expectativas acadêmicas dos professores em relação aos estudantes de famílias de baixa renda são menores ao comparar com as expectativas docentes de estudantes que vem de famílias de alta renda.

Este modo de perceber as famílias pobres foi denominado por Bronfenbrenner (1996) de "modelo de déficit". Ao se referir às atividades profissionais no campo do desenvolvimento, Bronfenbrenner considera que os profissionais estão sempre procurando algo de errado em alguém, seja no indivíduo ou na família, ou ainda no grupo do qual faz parte. Portanto, essas práticas tornam-se comuns na sociedade. Nesse sentido, percebe-se um número significativo de profissionais, tanto no setor público quanto no privado, empregados apenas para apontar os defeitos que estão supostamente na pessoa ou na família e executar procedimentos corretivos, sem esperança de efetuar uma melhora significativa e duradoura nesses sujeitos.

Para conhecer como se desenvolvem essas famílias e suas interações com os demais ambientes que as influenciam, é necessário estudar instituições e profissionais que atuam com pessoas em situação de vulnerabilidade social, visto que, provavelmente suas ações e interações são construídas a partir de ideias e crenças sobre esse grupo. Estas ações que se sustentam em crenças positivas ou negativas atuam de modo a ativar os potenciais resilientes na família ou não (Yunes, 2003).

Por fim, investigar a percepção dos professores possibilita não apenas conhecer o que eles pensam acerca das famílias, mas também identificar se eles acreditam na capacidade de resiliência das pessoas que enfrentam dificuldades, especialmente as advindas da pobreza. Ademais, permite compreender se os docentes sustentam sua prática profissional na garantia dos direitos das famílias ou apenas como mantenedora da ordem social. Neste sentido, o objetivo geral da presente pesquisa é investigar a resiliência familiar do ponto de vista de professores acerca das famílias de seus alunos em situação de vulnerabilidade social.

\section{Método}

\section{Ambiente da Pesquisa}

O estudo foi realizado em uma escola estadual de $1^{\circ}$ ao $5^{\circ}$ localizada na periferia da cidade de Belém do Pará, e o critério de escolha da referida escola foi por conveniência, 
visto que os pesquisadores tinham contatos com os diretores da escola que facilitaram a execução da pesquisa na escola.

\section{Participantes}

Participaram deste estudo onze professores de $1^{\circ}$ a $5^{\circ}$ ano que trabalham na escola pública mencionada no item anterior, a seleção desta amostra foi aleatória. Os professores tinham idade média de 47,63 anos, 81,81\% ( $n=9)$ trabalhavam mais de 4 anos na escola, $81,81 \%(n=9)$ tinham graduação em Pedagogia, 18\% ( $n=2)$ eram licenciados em matemática e $81,81 \%(n=9)$ possuíam especialização. Por questões éticas, os profissionais foram identificados por nomes fictícios de acordo com a ordem das entrevistas realizadas.

\section{Instrumentos e Técnicas}

Entrevista semiestruturada - a entrevista semiestruturada realizada com os participantes teve como objetivo investigar a resiliência familiar do ponto de vista de professores acerca das famílias de seus alunos em situação de pobreza, famílias com média de renda abaixo de um salário mínimo. Antes de iniciar as perguntas, foi explicado o conceito de resiliência para os participantes, visto que nenhum demonstrou conhecimento acerca do tema. O roteiro da entrevista foi construído com base na literatura acerca da resiliência familiar para identificar a percepção dos docentes acerca das famílias de seus alunos e, também, continha perguntas acerca da caracterização dos professores (Idade, tempo de formação e trabalho na escola, graduação e pós-graduação, série que ministra aula). Esta entrevista foi realizada com cada professor ao final do seu horário de trabalho e teve a duração média de 40 minutos.

Entrevista coletiva - o objetivo principal desta entrevista foi compreender a resiliência familiar sob a ótica das participantes. Para isto foram construídas três Situações Estruturadas de Investigação (SEI) (Silva, Pontes, Santos, \& Maluschke, 2011). Utilizou-se esta estratégia para facilitar a revelação pelos participantes de suas percepções sobre aspectos relativos à resiliência que não foram mencionados nas entrevistas individuais.

As SEIS foram construídas pelos autores para 0 presente estudo e consistiam em situações hipotéticas de famílias pobres comumente encontradas no cotidiano da instituição. Situação hipotética 1: A família um era composta por pai, mãe e dois filhos que apresentavam um bom desempenho acadêmico apesar das dificuldades relacionadas a pobreza. Situação hipotética 2: A família dois também era formada por pai, mãe e dois filhos, entretanto, as crianças não tinham desenvolvimento acadêmico satisfatório. Diante destas duas histórias, foram formuladas perguntas que tentaram identificar as razões percebidas pelos professores para o desempenho diferente nas duas famílias. Esta entrevista foi realizada em dois momentos, cada entrevista contou com quatro e três participantes e teve duração de uma hora e meia.

\section{Procedimentos de Coleta e de Análise dos Dados}

A primeira etapa deste estudo foi a submissão do projeto ao comitê de ética da Universidade Federal do Pará e após a aprovação ( $n^{\circ}$ do parecer 865.235) e foi realizado contato com a direção da escola. Com a autorização da direção, os professores das turmas de $1^{\circ}$ a $5^{\circ}$ ano foram convidados para participar do estudo. Após o aceite dos professores através da assinatura do Termo de Consentimento Livre Esclarecido, foi iniciada a marcação das entrevistas individuais sendo realizadas semanalmente nos horários estabelecidos pelos professores, geralmente ao final de suas aulas, e os dados foram posteriormente transcritos para a análise.

Participaram da entrevista individual onze professores e na entrevista coletiva foram sete docentes. Foram realizadas duas entrevistas coletivas, sendo que na primeira participaram quatro professores e na segunda três professores. Os demais professores não puderam participar por questões pessoais.

A análise dos dados foi realizada por meio da análise de conteúdo de Bardin (2011) e na literatura da resiliência familiar de Walsh (2005), além disso, utilizou-se o software Nvivo 10. Para tanto foram cumpridas as seguintes etapas: (a) organização e gerenciamento das fontes de dados no software; (b) codificação das fontes; (c) visualização dos resultados de codificação e (d) criação de gráficos com as categorias e subcategorias.

\section{Resultados e Discussão}

Os resultados estão apresentados de acordo com as categorias construídas com base no modelo de resiliência familiar de Walsh (2005), que são: sistema de crenças, padrões organizacionais e processo de comunicação, e suas respectivas subcategorias. Ressalta-se que, apesar das categorias serem pré-estabelecidas, elas foram consideradas em função do conteúdo emergente da fala dos professores, o que gerou a categoria família desestruturada, que emergiu com frequência nos discursos dos participantes. A Figura 1 representa as categorias e subcategorias encontradas no estudo.

Na figura 1 apresenta-se a frequência de cada categoria e subcategoria no estudo. A categoria com maior destaque foi Padrões organizacionais, que apareceu no discurso dos onze participantes. Todos os profissionais, em algum momento, mencionaram as subcategorias presentes nesta categoria, sendo que a subcategoria colaboração $e$ compromisso emergiu na fala de 10 docentes.

O sistema de crenças foi abordado por sete profissionais, sendo que a subcategoria com maior destaque foi espiritualidade. A categoria menos citada foi processo de comunicação que fora mencionada por seis docentes. 


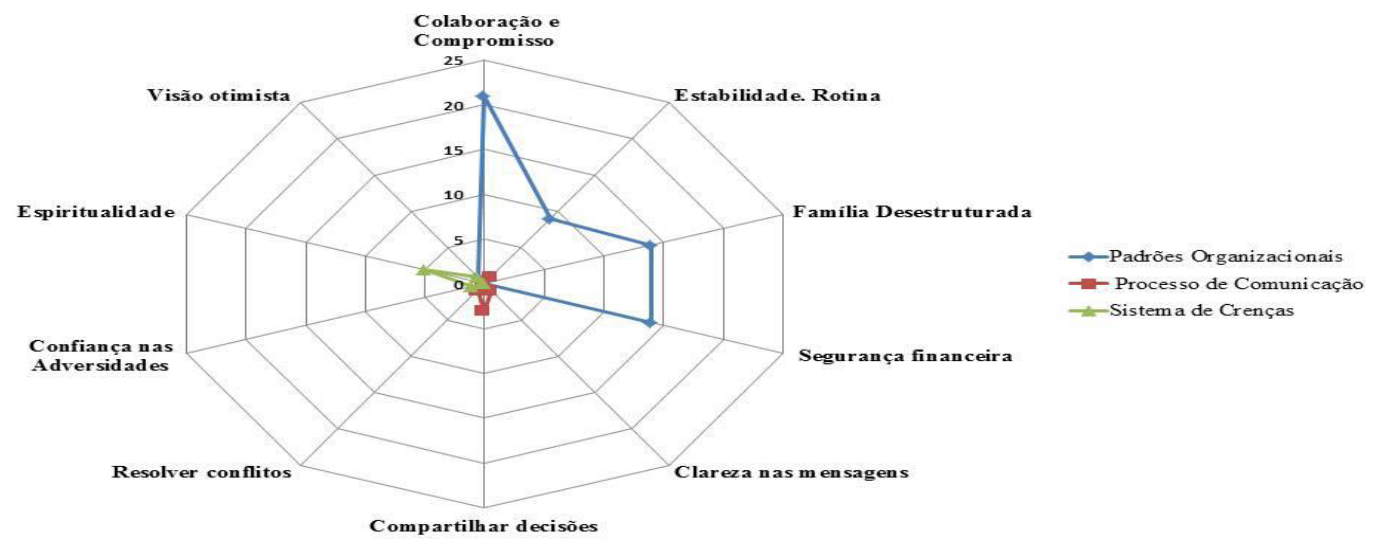

Figura 1. Processos-Chave da Resiliência Familiar.

\section{Padrões Organizacionais}

A principal categoria do modelo de Walsh (2005) emergente neste estudo foi os Padrões Organizacionais, descritos como "amortecedores dos choques familiares" que correspondem aos recursos (econômicos e sociais) que as famílias mobilizam para resistir ao estresse e se reorganizar para se adequarem às mudanças que podem ocorrer. A categoria Padrões Organizacionais é constituída, neste estudo, pelas subcategorias: colaboração e compromisso, estabilidade na rotina e segurança financeira. No entanto, com base nos dados obtidos, foi adicionada a este grupo a categoria família desestruturada, uma vez que esta apresentou-se com frequência alta nos discursos dos participantes.

A subcategoria colaboração e compromisso foi a que obteve maior destaque, com a menção de dezdocentes. Em sequência, nove participantes consideraram aspectos referentes à estabilidade na rotina como fundamental para o funcionamento familiar. A subcategoria família desestruturada apareceu também na fala de nove profissionais que expuseram sua percepção para descrever os grupos familiares e a última subcategoria emergente foi segurança financeira onde sete docentes descreveram suas percepções acerca do programa bolsa família e sobre os beneficiários.

Colaboração e compromisso é para Walsh (2005) um dos elementos fundamentais para o processo de resiliência familiar, e relaciona-se com o auxílio que os pais dão aos fiIhos na vida acadêmica. Nesta subcategoria, os professores consideraram importante a participação dos pais na escola e o acompanhamento em casa. Porém, destacaram a ausência de acompanhamento em casa como uma das causas para o pouco desenvolvimento das crianças, como pode ser observado na fala da professora Taís: "mas sinceramente se tivesse mais um acompanhamento, a educação seria muito diferente. Eu falo pra eles na reunião "gente, vocês têm que acostumar as crianças a estudar um pouco em casa" mas poucos escutam." (Professora Taís - entrevista individual).

Apesar de conhecedores da condição de pobreza em que vivemas famílias de seus alunos, os docentes não rela- cionaram estas dificuldades econômicas com os problemas de aprendizagem das crianças, nem tampouco com a pouca colaboração e compromisso dos pais com as atividades escolares dos filhos. Além do mais, percebe-se na fala acima que os professores de certa forma responsabilizam os pais pelo não aprendizado de seus filhos.

Eu particularmente acho que sintoma de pobreza não quer dizer falta de aprendizagem, eu acho que falta é dedicação porque eu tenho na minha sala pais que são analfabetos, mas que a filha está super bem, entendeu? Mas outros que nem são analfabetos não estão nem aí, então eu acho que falta aqui na escola é a dedicação familiar. (Professora Carla-entrevista coletiva).

Os dados revelaram que os professores identificaram o analfabetismo como uma característica que marca os responsáveis/pais das crianças que frequentam a escola. No entanto, não pareceram considerar que este seja um fator que contribua para o não acompanhamento dos filhos nas atividades escolares. Além disso, interessante destacar que a professora se referiu à pobreza como "sintoma". Com esta única palavra percebe-se que ela atribui a pobreza como algo negativo, e de fato viver na pobreza não é um fator de proteção, mas a forma como foi expressada pela participante parece que ela se refere a uma doença que precisa ser curada e sabe-se que pobreza é uma condição social onde o indivíduo muitas vezes não tem recursos suficientes para manter seus cuidados e necessidades básicas e logo isso acaba por se refletir em outros contextos, como por exemplo, a escola.

Para Mazzotti (2006), a visão dos professores de escolas públicas do Rio de Janeiro sobre a família dos alunos é marcada pela pobreza e analfabetismo. Porém, os professores não conseguem relacionar tais aspectos com as dificuldades no aprendizado dos alunos e consideram que o responsável pelas crianças não considera a educação importante (Yunes, 2003).

A estabilidade na rotina é outro elemento fundamental para o bom funcionamento familiar, ou seja, estabilidade de 
papéis, regras, horários e padrões de interação previsíveis e consistentes. A estabilidade na rotina familiar permite que seus membros saibam o que se espera deles e o que esperar do outro, além de manter o contato regular e vínculos entre as pessoas. Os estudos têm demonstrado significativo impacto da rotina na organização da família e no desenvolvimento humano (Silva \& cols., 2010)

Os participantes reconheceram que a rotina é um elemento importante para o bom funcionamento de uma família, contribuindo de modo especial para o desenvolvimento das crianças. Entretanto, na visão dos participantes, os pais não organizavam a rotina dos filhos, o que muitas vezes implicava na perda de aula, principalmente às segundas-feiras, já que os pais não conseguiam levar os filhos para a escola, conforme pode ser observado na fala a seguir: "eles saem domingo e não querem nem saber da rotina da semana. Então, eu acho assim, essas famílias muito irresponsáveis, eu acho, vou te repetir não vou te generalizar todas as famílias aqui, mas a maioria é." (Professora Daise - entrevista individual).

A subcategoria família desestruturada foi definida de acordo com o relato dos participantes. Esta subcategoria referiu-se à composição familiar, ou seja, as famílias que não se encaixavam no perfil de família nuclear eram vistas pelos professores como uma configuração negativa, observou-se que os professores trabalham com a ideia de que a família ideal é a tradicional composta por pai, mãe e filhos.

Hoje a família ta muito desestruturada, são poucos que tão com pai e mãe, a maioria é mãe solteira ou filho que tá com a mãe e o padrasto entende?...e dificulta o nosso trabalho, queira ou não uma estrutura familiar é uma estrutura familiar (Professora Fátima-entrevista individual).

Neste estudo foi frequente ouvir depoimentos de professores (as)apontando que as famílias são "desestruturadas", desinteressadas, carentes e violentas. Estas opiniões podem ser constituídas de explicações fáceis dadas pelos professores para o insucesso escolar de algumas crianças (Szymanski, 2010). Nesse âmbito, Szymanski (2010) considera ser necessário que a escola conheça a história das famílias e estabeleça uma relação de acolhimento. Um bom relacionamento precisa do interesse, da compreensão, do respeito e da valorização de ambas as partes: escola e família. A autora aponta que alguns aspectos como o diálogo, a abertura e a ausência de preconceito são atitudes que podem ajudar.

A desestrutura familiar também foi relacionada pelos participantes com as famílias lideradas pelas avós. De modo geral, a percepção dos participantes em torno do papel dos avós oscilou, sendo ora considerado como fator protetivo, uma vez que consideravam o modo rígido de educar adotado por estas adequado; ora como negativo para o desenvolvimento das crianças, pois em alguns casos davam mais carinho e menos limites do que as mães, nas próximas falas fica evidente tal afirmação: "eu gosto muito quando eles estão com avô, o avô dá aquela educação [antiga] eu gosto. A avó ainda tem aquele pulso antigo, forte, que ajeita mesmo" (Professora Sônia-entrevista individual);"'muita criança cria- da por avó, e a avó às vezes dá muito mimo" (Professor Ronaldo-entrevista individual).

Minuchin (1985), pautado na discussão sobre teoria sistêmica das famílias, aponta que existem momentos em que as famílias irão passar por mudanças. O modo como as famílias se reorganizam diante das mudanças é que tornará o ambiente familiar saudável ou não. A questão central não é a composição familiar, mas o processo de reorganização do sistema, diante das necessidades do sistema e nas falas acima percebe-se que os professores não trabalham com a concepção de diferentes configurações familiares existentes, mas sim com a percepção da família nuclear como a mais saudável para o desenvolvimento de seus membros. Outro dado preocupante observado nas falas dos professores é como eles associam que a punição e práticas coercitivas influenciam positivamente na educação das crianças conforme foi observado quando uma das professoras aponta que gosta "daquela educação" praticada por determinada avó (Silva, 2010; Yunes, 2003; Walsh, 2005).

No modelo de Walsh (2005), a subcategoria segurança financeira está presente ao discutir as políticas sociais que funcionam como amortecedores criados para propiciar o bem-estar das famílias diante de mudanças sociais e econômicas drásticas. As falas dos professores revelaram suas impressões acerca do Programa Bolsa Família (PBF) e sua contribuição às famílias envolvidas. Os participantes destacaram aspectos negativos, uma vez que na visão deles, as famílias que recebem o recurso financeiro são dependentes de tal programa e diante disso preferem não trabalhar, conforme se observa no próximo relato: "eu acho o bolsa bom, melhorou a frequência da criança, mas os pais ficam preguiçosos e "vagabundos" no sentido de que não querem mais trabalhar e só ficar às custas disso, não acho certo". (Professor Ronaldo-entrevista individual).

Além disso, os participantes destacaram o fato de as famílias se preocuparem com a frequência da criança em função do benefício. Para os professores, os pais temem perder o recurso e por isso garantem a frequência dos filhos na escola e não por considerarem importante que seus filhos aprendam os conteúdos são trabalhados no contexto escolar.

hoje a família não se preocupa tanto com a aprendizagem do seu filho ela tá preocupada com a Bolsa (PBF), ela traz a criança, mas a preocupação dela é a bolsa que ela vai receber no final do mês, não tem preocupação que o filho venha pra aprender e coloca o filho, colocou pronto, vai embora, né? (Professora Marta- entrevista individual).

A literatura especializada que investiga os impactos do PBF revela o aumento da frequência escolar e do número de matrículas nas escolas de crianças beneficiadas pelo programa. A probabilidade de uma criança beneficiária faltar à escola é 3,6\% menor do que das crianças não-beneficiárias e os índices de evasão são de 1,6\% menores entre as beneficiárias. E em relação à dependência os estudos mostram que mais da metade dos beneficiários tem uma ocupação profissional; logo, além de demonstrar uma visão 
preconceituosa e pessimista sobre o PBF, percebe-se a falta de informação de tais professores sobre o reflexo deste determinado programa social na vida das famílias de seus alunos (Soares, Ribas, \& Osório, 2010).

\section{Sistema de Crenças}

O sistema de crenças é um dos elementos do modelo de Walsh (2005) e corresponde ao modo como as famílias enxergam as dificuldades, quais meios encontram para enfrentar problemas e se a família tem a presença de espiritualidade que a influência nesse processo. O Sistema de crenças é composto pelas subcategorias: visão otimista, confiança nas adversidades e espiritualidade.

A subcategoria que mais se destacou na fala dos professores foi a espiritualidade, mencionada por sete docentes. De maneira geral, os professores consideraram que a crença religiosa, isto é, a vivência da espiritualidade, é um dos fatores que contribuía significativamente para o fortalecimento familiar diante de adversidades. As demais subcategorias apareceram no discurso de três professores.

$\mathrm{Na}$ visão dos entrevistados, as famílias que têm contato e participação com instituições religiosas têm maiores probabilidades de viver sem conflitos familiares. Segundo a professora Sônia, a relação com Deus auxiliava na superação das dificuldades. No entanto, na visão dela as famílias atendidas pela escola também não valorizavam a espiritualidade:"a família que tem aquela estrutura com Deus, toda aquela educação dos princípios ela consegue com certeza muita coisa, pode estar na maior dificuldade, mas não cai. Mas aqui [na escola] eles querem só festa." (Professora Sônia - entrevista coletiva).

A percepção dos professores acerca da religião é reforçada pela literatura sobre fatores de proteção, que aponta a religiosidade como um aspecto que age empoderando as famílias, tornando-as mais capazes para enfrentar as situações de vulnerabilidade. O que a literatura não reforça é a percepção negativa diante da presença da espiritualidade em famílias em situação de pobreza (Poletto \& Koller, 2008).

Na subcategoria visão otimista, a professora Adriana considerou primordial que as famílias sejam otimistas, mesmo nas adversidades. Na percepção desta docente, a família que possui confiança na superação de problemas é aquela que valoriza a educação e acredita que através do estudo o grupo familiar pode superar obstáculos, mas a participante destacou que as famílias da escola não dão valor à educação.

[...] mas eu percebo assim que é a minoria que acredita nisso entendeu? E mais, parece assim que eles não veem o estudo como uma possibilidade de um dia melhorar, entendeu? De um dia a criança vim a melhorar aquela situação ali que ela vive, entendeu? Muitos não veem a educação assim. (Professora Adriana - entrevista individual).

A literatura aponta ser relevante explorar os aspectos positivos que indivíduos e famílias possuem, numa tentativa de fazer famílias e profissionais adotarem uma visão mais aberta e apreciativa dos potenciais e capacidades humanas. Não significa desconsiderar os aspectos negativos que se fazem presente, mas sim, construir uma visão do ser humano com base nos aspectos "virtuosos"(Yunes, 2003; Szymanski, 2010), assim como propiciar que as famílias enxerguem as dificuldades como transitórias e superáveis; os dados das falas dos professores demonstraram o contrário, no sentido da relevância que estes deram para aspectos considerados negativos nas famílias. É importante também que o contexto escolar seja ativo no processo de participação dos pais dos alunos nas questões escolares, pois a escola como um ambiente social deve utilizar estratégias para que esses indivíduos possam valorizar tal ambiente e que o diálogo família/escola ocorra de maneira mais próxima (Yunes, 2003; Szymanski, 2010).

\section{Processo de Comunicação}

A última categoria, processo de comunicação, corresponde à maneira como a família se comunica entre si e como resolvem problemas que afetam a todos os membros (Walsh, 2005) e é constituída pelas subcategorias encontradas no presente estudo: resolver conflitos, compartilhar decisões e clareza nas mensagens. A subcategoria com maior destaque, compartilhar decisões, foi mencionada por seis profissionais e as demais foram abordadas por quatro participantes.

A subcategoria compartilhar decisões refere-seà participação dos membros de uma família na resolução de conflitos. A professora Taís associou o compartilhamento de decisões com a ida dos pais à escola para conversar com os professores sobre o desempenho acadêmico de seus filhos. Segundo ela, a procura dos pais pela escola é um indicador de que eles estão compartilhando, através do diálogo, preocupações, informações e decisões sobre seus filhos, porém, ressaltou que esse comportamento é uma exceção nas famílias da escola: "é, a comunicação entre eles é uma coisa muito importante. Às vezes vem pai falar comigo, então eles tão conversando sobre a menina, né? Mas é a exceção aqui, a maioria não é assim." (Professora Taís - entrevista individual).

A literatura aponta que o diálogo, a comunicação entre os membros de um grupo familiar torna os relacionamentos mais saudáveis. De Antoni, Barone e Koller (2006) observaram em estudo de caso realizado para identificar fatores de risco e proteção em uma família pobre residente em um bairro periférico de Porto Alegre, que a ausência de diálogo entre os membros da família ocasionava conflitos dentre estes: violência conjugal, violência entre pais e filhos e intolerância uns com os outros.

A subcategoria resolver conflitos faz parte da categoria processo de comunicação e foi considerada pela professora Luiza como fundamental para o funcionamento da família. Em sua fala, destacou que os membros que compõem o grupo familiar devem estar unidos e dialogar sobre as dificuldades encontradas. No entanto, considerou que estes aspectos são difíceis de serem encontrados nos sistemas familiares. 
[...] eles [membros da família] se respeitarem mutuamente, eles conversarem entre si sobre as dificuldades que estão ocorrendo então é isso que a familia precisa ter. Porque hoje em dia essas famílias vivem com o problema muito pra si, mas é difícil encontrar união nas famílias daqui (escola). (Professora Luiza - entrevista coletiva).

$\mathrm{Na}$ subcategoria clareza nas mensagens, os professores destacaram a importância de existir o diálogo nas famílias; entretanto, todos os participantes salientaram a ausência de processos de comunicação nas famílias atendidas pela escola. A professora Taís afirmou que a comunicação entre os pais é um elemento fundamental para que a família se desenvolva de modo satisfatório e, segundo ela, é mais fácil de se trabalhar com o grupo familiar que se comunica, sendo que em sua percepção, as famílias divorciadas, frequentes na escola, se comunicam de forma pouca clara o que as torna mais difíceis.

Walsh (2005) aponta que a clareza na comunicação é essencial para o funcionamento familiar, ou seja, uma comunicação direta onde os membros dizem o que querem. Manter a comunicação aberta propicia o funcionamento saudável das famílias. A comunicação pode ser definida como troca de informações e também ser útil para a resolução de problemas entre os membros. A participante Sônia também considerou importante o diálogo para o bom funcionamento familiar, no entanto, ela também destacou a ausência de conversa nas famílias: "o que eu vejo muito assim é a falta de diálogo. Então tem que conversar, saber. Uma criança precisa que alguém pergunte "o que você fez?ai aqui na escola é tudo jogado" (Professora Sônia-entrevista coletiva).

Poletto e Koller (2008) descreveram alguns fatores de proteção para o fortalecimento da resiliência famílias e dentre estes a comunicação é considerada um importante aspecto, mesmo quando as famílias se encontram expostas a ameaças ou situações de risco variadas. De maneira geral,os dados mostraram que os docentes identificaram os elementos da resiliência familiar, mas consideraram que as famílias de seus alunos não apresentavam estas características.

\section{Considerações Finais}

O estudo contribuiu, na medida em que se propôs a descrever a percepção que os professores de uma escola pública de uma região periférica de Belém têm sobre a possibilidade de resiliência dos seus alunos e de suas respectivas famílias. Os dados mostraram que os docentes atuavam com uma visão pessimista em relação a seus usuários e isso preocupa, uma vez que as baixas expectativas dos professores sobre os alunos podem resultar em menores oportunidades de aprendizagem e diminuição da autoestima dos estudantes sobre os quais se formaram suas expectativas, o que de certa forma dificulta ainda mais seu desempenho.

Ademais, possuem uma visão estereotipada sobre família, pois ainda mantêm a ideia de família nuclear como a ideal e as demais configurações são percebidas como de- sestruturadas. E estes profissionais, apesar de atuarem em uma escola de uma região considerada periférica da cidade, parecem não compreender a pobreza como fenômeno multidimensional que influencia negativamente as famíliasem diferentes aspectos e possuem uma visão estigmatizada da pobreza, como se esta fosse um sintoma, uma doença que precisa ser curada e vinculam o insucesso familiar à pobreza.

Este estudo teve algumas limitações principalmente no que se refere à coleta de dados uma vez que os docentes não dispõem de tempo para participar de situações não previstas em sua rotina profissional, como responder a questionários e participar de entrevistas. Esta dificuldade explica o número pequeno de participantes no estudo. Sugere-se que em futuras pesquisas sejam pensadas estratégias que garantam a maior participação dos docentes. Ademais, acredita-se ser necessária a realização de projetos de intervenção que fortaleçam os aspectos sadios e de sucesso do grupo familiar dentro do espaço escolare oportunizem a interação família e professores.

\section{Referências}

Angst, R. (2017). Psicologia e resiliência: uma revisão de literatura. Psicologia argumento, 27(58), 253-260.

Bronfenbrenner, U. (1996). A ecologia do desenvolvimento humano: experimentos naturais e planejados. (M. A. V. Veronese, Trad.). Porto Alegre: Artmed. (Trabalho original publicado em 1979).

Bronfenbrenner, U. (2011). Bioecologia do desenvolvimento humano: tornando os seres humanos mais humanos. Artmed Editora.

Bardin, L.(2011). Análise de conteúdo. São Paulo: Edições 70

Chequini, M. C. M. (2014). A relevância da espiritualidade no processo de resiliência. Psicologia Revista, 16(1/2), 93-117.

De Antoni, C.; Barone, L. R.; Koller, S. H. (2006). Violência e pobreza: um estudo sobre vulnerabilidade e resiliência familiar. In: Dell'Aglio, D. D.; Koller, S. H.; Yunes, M. A. M. (Orgs.), Resiliência e psicologia positiva: Interfaces do risco à proteção (pp. 141-171). São Paulo, SP: Casa do Psicólogo.

Dessen, M. A.; Polônia, A. D. C. (2007). A família e a escola como contextos de desenvolvimento humano. Paidéia, 17(36), 21-32. doi: 10.1590/S0103-863X2007000100003

García, V. E. C.; Gómez, V. L. A.; Gómez, D. S. M.; Marín, I. P. G.; Rodas, A. M. C. (2016). Madres, padres y profesores como educadores de la resiliencia en niños colombianos. Psicologia Escolar e Educacional, 20(3), 569-579. doi: 10.1590/21753539201502031049

Germano, I. M. P.; Colaço, V. F. R. (2012). Abrindo caminho para o futuro: redes de apoio social e resiliência em autobiografias de jovens socioeconomicamente vulneráveis. Estudos de Psicologia, 
17(3), 381-387. doi: 10.1590/S1413-294X2012000300005

Kagan, R.; Henry, J.; Richardson, M.; Trinkle, J.; LaFrenier, A. (2014). Evaluation of Real Life Heroes treatment for children with complex PTSD. Psychological Trauma: Theory, Research, Practice, and Policy, 6(5), 588. doi: 10.1037/a0035879

Libório, R. M. C.; Ungar, M. (2010). Resiliência oculta: a construção social do conceito e suas implicações para práticas profissionais junto a adolescentes em situação de risco. Psicologia Reflexão e Crítica, 23(3), 476-484. doi: http://dx.doi.org/10.1590/S010279722010000300008 .

Mazzotti, A. J. (2006). O “ aluno da escola pública”: o que dizem as professoras. Revista Brasileira de Estudos Pedagógicos, 87(217).

Minuchin, P. (1985). Families and individual development: provocations from the field of family therapy. Child Development, v. 56, 289-302.

Miranda, C. S. S. (2015). Resiliência Familiar e Risco Psicossocial: Estudo das percepções das famílias e dos profissionais que as acompanham. Dissertação de mestrado, Universidade do Minho, Braga, Portugal.

Picanço, A. L. B. (2012) A Relação entre Escola e Família: as suas implicações no processo de ensino-aprendizagem. Dissertação de mestrado. Escola Superior de Educação João de Deus Lisboa, Portugal.

Poletto, M.; Koller, S. H. (2008). Contextos ecológicos: promotores de resiliência, fatores de risco e de proteção. Estudos de Psicologia (Campinas), 25 (3), 405-416. doi: 10.1590/S0103166X2008000300009

Rodovalho Garcia, N.; Boruchovitch, E. (2014). Atribuições de causalidade para o desempenho escolar e resiliência em estudantes. Psico-USF, 19(2). doi: 10.1590/141382712014019002003

Rooke, M. I.; Pereira-Silva, N. L. (2012). Resiliência familiar e desenvolvimento humano: análise da produção científica. Psicologia em Pesquisa, 6(2), 179-186. doi: 10.24879

Silva, M. O. (2010). Pobreza, desigualdade e políticas públicas: caracterizando e problematizando a realidade brasileira. Revista Katálysis, 13(2), 155-163. doi: 10.1590/S141449802010000200002
Silva, S. S. C.; Santos, T. M.; Pontes, F. A. R.; Maluschke, J. B. (2011). Adaptação de Famílias Ribeirinhas: uma proposta adaptada ao contexto. Revista Interinstitucional de Psicologia, 4(2), 253-263.

Silva, S. S. C.; Pontes, F. A. R.; Santos, T. M.; Maluschke, J. B.; Mendes, L. S. A.; Reis, D. C.; Silva, S. D. B. (2010). Rotinas familiares de ribeirinhos amazônicos: uma possibilidade de investigação. Psicologia: teoria e pesquisa, 26(2), 341-350.

Soares, F.; Ribas, R. P.; Osório, R. G. (2010). Evaluating the impact of Brazil's Bolsa Família. Latin American Research Review, 45, 173-90.

Szymanski, H.(2010). A relação família/escola: desafios e perspectivas ( $2^{\mathrm{a}}$ ed.). Brasília: Liber Livro.

Tancredi, R. M. S. P.; Reali, A. M. M. R. (2001). Visões de professores sobre seus alunos: um estudo na área da educação infantil. Trabalho apresentado na $24^{\text {a }}$ Reunião Anual da ANPED (pp.1-16). Caxambu.

Walsh, F. (2005). Fortalecendo a Resiliência Familiar. Editora Roca.

Yunes, M. A. (2001). Questão triplamente controvertida da resiliência em famílias de baixa renda. Tese de Doutorado, Pontifícia Universidade Católica de São Paulo, São Paulo.

Yunes, M. A. M. (2003). Psicologia positiva e resiliência: o foco no indivíduo e na família. Psicologia em estudo, 8(1), 80-95. doi: $10.1590 / \mathrm{S} 1413-73722003000300010$

Yunes, M. A. M.; Szymanski, H. (2016). Crenças, sentimentos e percepções acerca da noção de resiliência em profissionais da saúde e da educação que atuam com famílias pobres. Psicologia da Educação. Programa de Estudos Pós-Graduados em Educação: Psicologia da Educação,(17),2175-3520.

Yunes, M. A. M.; Mendes, N. F.; Albuquerque, B. D. M. (2005). Percepções e crenças de agentes comunitários de saúde sobre resiliência em família monoparentais pobres. Texto \& Contexto Enfermagem, 14, 24-31. doi: 10.1590/S0104-07072005000500003

Zhang, Y. (2012). Educational expectations, school experiences and academic achievements: A longitudinal examination. University of Pennsylvania. Gansu Survey of children and families. c4

Recebido: 23 de abril de 2017 Aceito: 15 de agosto de 2018

Trabalho derivado da dissertação de mestrado intitulada Resiliência em família de baixa renda: percepção de professores e familiares (2015). Apoio financeiro da Coordenação de aperfeiçoamento de Nível Superior (CAPES)

(cc) EY License information: This is an open-access article distributed under the terms of the License (type CC-BY), which permits unrestricted use, distribution and reproduction in any medium, provided the original article is properly cited. 